\title{
Determination of interstitial collagenase (MMP-1) in patients with rheumatoid arthritis
}

Shingo Maeda, Takashi Sawai, Miwa Uzuki, Yuichi Takahashi, Hiroshi Omoto, Masayuki Seki, Minoru Sakurai

\begin{abstract}
Objectives-To investigate whether interstitial collagenase (MMP-1) concentration in synovial fluid can be useful as a marker for disease activity in rheumatoid arthritis (RA), to determine the main route by which collagenase degrades the matrix of articular cartilage, and to investigate if an imbalance between metalloproteinases (MMPs) and tissue inhibitor of metalloproteinases (TIMP) is responsible for the activity of MMPs in RA.

Methods-Collagenase concentrations were measured in synovial fluid and paired serum samples using a specific sandwich enzyme linked immunosorbent assay. Collagenase activities were also assayed in synovial fluid samples. Synovial tissues obtained from the same patient were examined by immunohistochemical staining and the numbers of cells expressing collagenase were counted.
\end{abstract}

Results-Collagenase concentrations in synovial fluid did not correlate with $C$ reactive protein and collagenase levels in serum, but did correlate positively with the degree of synovial inflammation, and increased with increasing numbers of cells identified as expressing collagenase in synovial tissue. Collagenase activities did not correlate with TIMP-1 concentrations, but did correlate strongly with the ratios of collagenase concentration to TIMP-1 $(r=0.73)$.

Conclusion-The collagenase concentration in synovial fluid cannot be used as a marker for systemic disease activity, but can be used as a marker for the degree of synovial inflammation in the joint from which the sample is aspirated. In advanced RA, most of the collagenase is probably produced in synovial lining cells and released into synovial fluid, where it degrades the matrix of articular cartilage. may be of importance in the degradation of extracellular matrix of articular cartilage in RA.

(Ann Rheum Dis 1995; 54: 970-975)

Rheumatoid arthritis (RA) is characterised by chronic inflammation, which leads to degradation of the extracellular matrix and distortion of the architecture and function of An imbalance between MMP and TIMP the joints. The matrix metalloproteinases (MMPs) are a family of enzymes that can degrade all components of the extracellular matrix. ${ }^{1}$ Interstitial collagenase (E.C.3.4.24.7; MMP-1) is a member of the MMP gene family that cleaves the collagen triple helix to yield

Explants from human rheumatoid synovial tissue have been found to release large amounts of collagenase, ${ }^{3}$ and increased collagenase activity has been reported in rheumatoid synovial fluid. ${ }^{4}$ Collagenase was localised by immunostaining on the extracellular matrix components at the cartilage-pannus junction in $R A,{ }^{5}$ and immunohistochemical staining has subsequently shown it to be localised intracellularly in hyperplastic synovial lining cells of the rheumatoid synovium. ${ }^{6}$ However, it has also been reported that chondrocytes produce proteinases capable of degrading osteoarthritic and normal human cartilage, ${ }^{78}$ and that the matrix of cartilage was severely degraded when living cartilage was placed in contact with synovium. ${ }^{9}$

Collagenases in cell and tissue cultures are commonly synthesised and secreted as inactive, latent forms. ${ }^{10}$ Procollagenase can be activated in culture medium by trypsin, ${ }^{11} 12$ chaotrophic agents, ${ }^{13} 14$ and mercurial compounds, ${ }^{15}$ and in vivo by stromelysin (MMP-3) ${ }^{16}$ Van Wart et al have proposed the 'cysteine switch' activation mechanism for members of the matrix metalloproteinase gene family, ${ }^{17}$ but the process by which activation is achieved in vivo remains unclear. Cawston et al purified a collagenase inhibitor synthesised by newborn rabbit bone in tissue culture ${ }^{18}$ that bound to purified collagenase with a $1: 1$ stoichiometry. The inhibitor, named TIMP (tissue inhibitor of metalloproteinase), interacted with the active form of collagenase to form a tight enzyme-inhibitor complex that differed from latent collagenase. ${ }^{19}$ Dean et al proposed that an imbalance of MMPs and TIMP contributed to the pathogenesis of osteoarthritis $(\mathrm{OA}) .^{20}$

There have been no reports of studies in which synovial fluid, serum, and synovium were obtained from the same RA patient and MMP contents of the samples measured. In this study we assayed collagenase concentrations in synovial fluid and serum to investigate whether those in synovial fluid could be useful as a marker for disease activity in RA. We also compared synovial fluid concentrations of collagenase with the numbers characteristic $1 / 4-3 / 4$ products. $^{2}$ 
of cells expressing collagenase in synovial tissue (demonstrated by immunohistochemical staining) in order to determine the main pathway taken by collagenase to degrade the matrix of articular cartilage in RA. In addition, we measured collagenase activities and concentrations of collagenase and TIMP to investigate if an imbalance between MMPs and TIMP is responsible for the activity of MMPs in RA.

\section{Patients and methods}

MONOCLONAL ANTIBODIES AGAINST

INTERSTITIAL COLLAGENASE (MMP-1)

Mouse monoclonal antibodies (clone $\mathrm{K} 5 \mathrm{E} 1$, K2F7, K4H11) against interstitial collagenase (MMP-1) purified from serum free culture medium of P12-4 fibrosarcoma were prepared by means of a modification of a method described previously. ${ }^{21}$ Purified procollagenase had an $M_{\mathrm{r}}$ value of 52000 . Analysis of the effect of monoclonal antibodies on collagenase by immunoblotting showed that the antibodies reacted specifically with collagenase that had identical $M_{\mathrm{r}}$ values.

\section{PATIENT SELECTION AND PREPARATION OF} SAMPLES

Synovial tissue, synovial fluid, and serum were obtained from patients with RA, all of whom met the American College of Rheumatology (formerly the American Rheumatism Association) criteria for the diagnosis of RA. ${ }^{22}$ Synovial tissue was obtained at the time of total knee joint replacement surgery, and synovial fluid was aspirated from the same joint. The synovial tissue was fixed in $4 \%$ paraformaldehyde dissolved in phosphate buffered saline solution (PBS) for two hours, and then wrapped in paraffin. Synovial fluid and serum samples were centrifuged to remove cells and debris, and stored frozen at $-70^{\circ} \mathrm{C}$ until required for assay.

IMMUNOHISTOCHEMICAL STUDIES AND QUANTIFICATION OF POSITIVE CELLS

For the immunohistochemical studies, sections of synovial tissue $2 \mu \mathrm{m}$ thick were mounted on slides. Endogenous peroxidase activity was blocked with $1 \%$ hydrogen peroxide in methanol for 30 minutes, followed by rinsing with PBS for 15 minutes. Normal horse serum was applied for 15 minutes as a blocking agent. This was followed by rinsing with PBS and application of the primary antibodies. The next day, the sections were rinsed with PBS and biotinylated secondary antibodies applied for 30 minutes. Streptavidin peroxidase was applied for 30 minutes. The sections were then exposed to diaminobenzidine and dilute hydrogen peroxide for seven minutes. The reaction was stopped with tap water, and the sections dehydrated and mounted.

The numbers of cells shown to express collagenase were counted on at least 20 different microscopic fields and the numbers averaged and graded on the following semiquantitative scale: grade $0=$ absent; $1+=1-5$ cells per high power field (hpf) $(\times 400)$; $2+=6-15$ cells $/ \mathrm{hpf} ; 3+=>15$ cells $/ \mathrm{hpf}$.

DOUBLE ANTIBODY SANDWICH ENZYME LINKED IMMUNOSORBENT ASSAY (ELISA) FOR COLLAGENASE

Collagenase concentrations were assayed using a specific sandwich ELISA. Ninety six well microtitre plates were coated overnight at $4^{\circ} \mathrm{C}$ with $10 \mu \mathrm{g} / \mathrm{ml}$ of $\mathrm{K} 5 \mathrm{E} 1$ in carbonate buffered saline solution. The plates were rinsed in $0.05 \%$ Tween 20 -PBS, and incubated for one hour at room temperature $\left(15^{\circ} \mathrm{C}\right)$ with Block Ace $^{R}$ (Dainippon Seiyaku Co Ltd) in PBS to block non-specific protein binding in the wells. (Block $\mathrm{Ace}^{\mathrm{R}}$ is a blocking reagent that contains $1 \%$ milk protein and organic acid buffer.) The blocker was rinsed from the plates and standard recombinant procollagenase or samples added for two hours at room temperature. Synovial fluid samples were diluted 1:1000 for assay with Block $A \mathrm{Ce}^{\mathrm{R}}$; serum samples were diluted 1:10. The plates were then rinsed three times and incubated with $\mathrm{K} 2 \mathrm{~F} 7$ for two hours at room temperature. The antibodies were rinsed from the plates, which were then incubated with streptavidin peroxidase for 30 minutes at room temperature before rinsed four times, followed by 10 minutes incubation with $o$-phenylenediamine. The reaction was stopped by addition of normal sulphuric acid, and the absorbance at $490 \mathrm{~nm}$ was measured spectrophotometrically.

The assays detected both procollagenase and activated collagenase binding TIMP with almost the same sensitivity. Free active collagenase was assayed to a slightly different degree of sensitivity, but a dose-response curve for free active collagenase was obtained. TIMP could not be assayed adequately.

ONE STEP SANDWICH ENZYME IMMUNOASSAY (EIA) FOR TIMP-1

TIMP-1 concentrations in synovial fluid were measured by means of sandwich EIA Kits purchased from Fuji Chemical Industries Ltd. The sandwich EIA quantitatively measures not only free TIMP but also TIMP complexed with collagenase. ${ }^{23-25}$

INFLAMMATION SCORES

The degree of synovial inflammation was analysed on haematoxylin and eosin stained sections using a modification of a method described previously. ${ }^{26}$ Inflammation scores were determined as the sum of three components: synovial lining thickness $(0=1-2$ cells; $1+=3-4$ cells; $2+=5-6$ cells; $3+=>6$ cells), lymphoid follicles $(0=0-1$ per low power field (lpf) $(\times 40) ; 1+=2-3 / \mathrm{lpf} ; 2+=4-6 / \mathrm{lpf}$; $3+=>6 / \mathrm{pp})$, and interfollicular features $(0=$ complete fibrosis; $1+=$ mononuclear cell infiltration $<33 \%$ of lpf; $2+=33-67 \%$; $3+=>67 \%$ ). They were then classified into four groups according to the semiquantitative scores: $0=$ class $0 ; 1-3=1+; 4-6=$ class $2+$; 7-9 $=$ class $3+$. 
COLLAGENASE ACTIVITY ASSAYS

Collagenase activities were assayed using the method reported previously. ${ }^{27}$ In this study, synovial fluids were assayed for collagenase activities after activation with L-1-tosylamide2-phenylethyl chloromethyl ketone (TPCK) treated trypsin. Fluorescein isothiocyanate labelled collagen was used as substrate. One unit of collagenase activity was defined as the amount of enzyme degrading $1 \mu \mathrm{g}$ of collagen per minute under the conditions used.

\section{STATISTICAL ANALYSIS}

Data were analysed by the non-parametric Mann-Whitney $U$ test, Student's paired $t$ test, and Pearson correlation coefficients. $P$ values less than 0.05 were considered significant.

\section{Results}

PATIENTS AND SAMPLE PREPARATION

Synovial fluid and serum samples were obtained from 41 patients ( 37 women and four men; mean age 60 years (range 32 to 89 years)). Synovial tissues were taken from 35 of these patients. TIMP-1 concentrations were assayed in samples from 35 patients, and collagenase activities measured in samples from 23.

\section{RELATIONSHIP BETWEEN COLLAGENASE} CONCENTRATIONS IN PAIRED SYNOVIAL FLUID AND SERUM SAMPLES

We measured collagenase concentrations in paired synovial fluid and serum samples from 41 patients. Collagenase concentrations in synovial fluids (mean 2361 (SD 2628) $\mathrm{ng} / \mathrm{ml}$ ) were significantly greater than those in sera $(25.6(21.9) \mathrm{ng} / \mathrm{ml})(\mathrm{p}<0.0001)$. No obvious relationship existed between the levels of collagenase in synovial fluid and serum $(r=0.207, \mathrm{p}=0.187)$, and we found no relationship between the concentrations in synovial fluid and those of $\mathrm{C}$ reactive protein in serum, or between collagenase concentration in synovial fluid and the ARA (1949) Stage \& Class criteria for the progression of rheumatoid arthritis and the functional

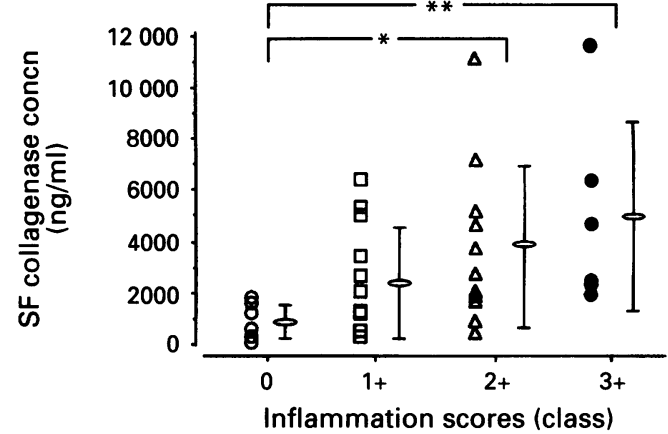

Figure 1 Relationship between synovial fluid concentrations of collagenase and inflammation scores. ${ }^{\star} p<0.05 ;{ }^{\star *} p<0.005$.

capacity of patients with the disease (data not shown). ${ }^{28}$

RELATIONSHIP BETWEEN SYNOVIAL FLUID CONCENTRATIONS OF COLLAGENASE AND INFLAMMATION SCORES

Figure 1 illustrates the relationship between the concentration of collagenase in synovial fluid and the inflammation score classes. Six patients were in class $3+, 11$ were in class $2+$, 12 were in class $1+$, and six were in class 0 . The concentrations of collagenase in synovial fluid from patients with class $3+$ inflammation ranged from 1991 to $11712 \mathrm{ng} / \mathrm{ml}$ (mean (SD) $4954(3723) \mathrm{ng} / \mathrm{ml}(\mathrm{n}=6))$; the values for class $2+$ patients ranged from 478 to $11158 \mathrm{ng} / \mathrm{ml}$ (3790 (3163) $\mathrm{ng} / \mathrm{ml}(\mathrm{n}=11))$; those of class $1+$ patients were from 320 to $6398 \mathrm{ng} / \mathrm{ml}(2400$ (2182) $\mathrm{ng} / \mathrm{ml}(\mathrm{n}=12))$; and those of class 0 patients ranged from 97 to $1820 \mathrm{ng} / \mathrm{ml}(953$ $(707) \mathrm{ng} / \mathrm{ml}(\mathrm{n}=6))$. A positive correlation was observed between the degree of synovial inflammation and the collagenase concentration in synovial fluid.

RELATIONSHIP BETWEEN GRADE FOR POSITIVE CELL COUNT AND COLLAGENASE

CONCENTRATIONS IN SYNOVIAL FLUID

Collagenase was immunolocalised in hyperplastic synovial lining cells in rheumatoid synovium. Figure 2 shows a haematoxylin and eosin stained section of synovial tissue

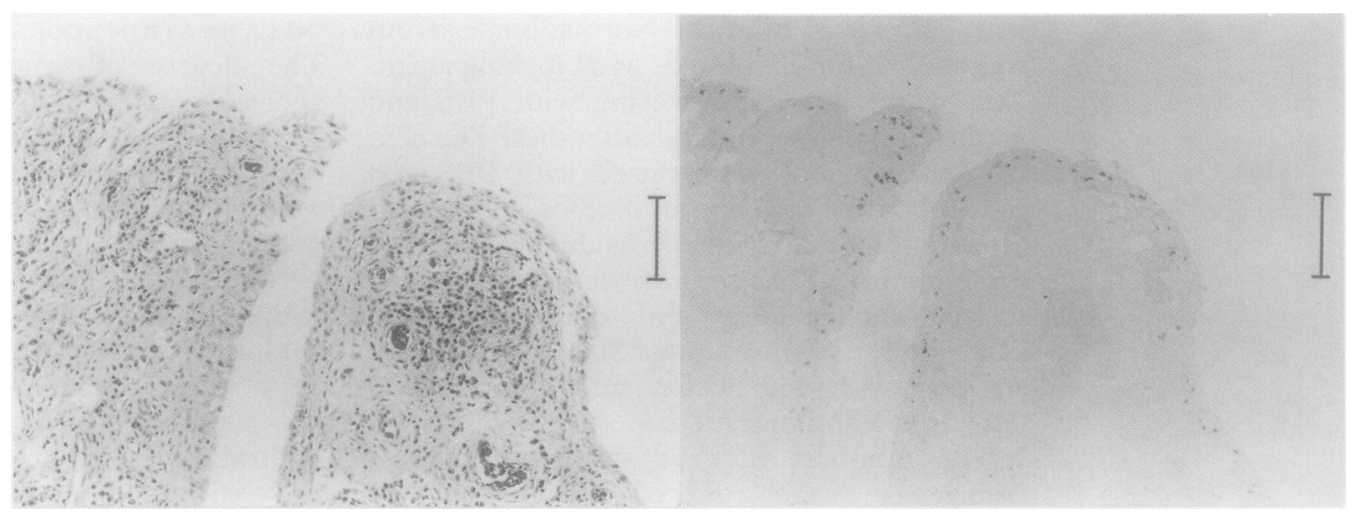

Figure 2 Haematoxylin and eosin stained section of rheumatoid synovial tissue (left), and immunolocalisation of collagenase in the same rheumatoid synovial tissue, showing positive cells in the hyperplastic synovial lining cells (right). Bar represents $100 \mu \mathrm{m}$. 


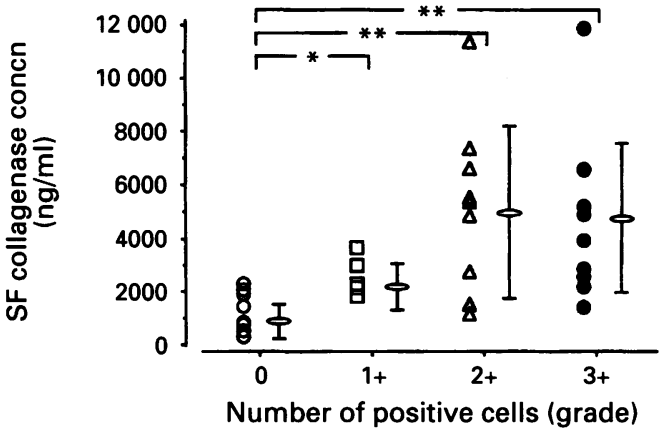

Figure 3 Relationship between the density of positive cells demonstrated by immunohistochemical staining and collagenase concentrations in synovial fluid $(S F)$. ${ }^{*} p<0.01 ;{ }^{*} p<0.001$.

and a serial section from the same synovium analysed for expression of collagenase by immunohistochemical staining. Very little staining was found in chondrocytes and fibroblasts at the cartilage-pannus junction.

With our system of grading by the number of cells immunohistochemically positive for collagenase expression, nine patients were grade $3+$, nine were grade $2+$, five were grade $1+$, and 11 were grade 0 . Figure 3 shows the collagenase concentrations in synovial fluid taken from patients belonging to each grade; concentrations in patients from grade 3+ ranged from 1189 to $11712 \mathrm{ng} / \mathrm{ml}$ (mean (SD) 4430 (3197) $\mathrm{ng} / \mathrm{ml}(\mathrm{n}=9)$ ); in grade $2+$ patients they were from 924 to $11158 \mathrm{ng} / \mathrm{ml}$ (4954 (3157) $\mathrm{ng} / \mathrm{ml}(\mathrm{n}=9))$; those in grade $1+$ patients ranged from 1609 to $3451 \mathrm{ng} / \mathrm{ml}$ (2346 (754) $\mathrm{ng} / \mathrm{ml}(\mathrm{n}=5))$; and concentrations in grade 0 patients ranged from 96 to $2040 \mathrm{ng} / \mathrm{ml}(842$ (712) $\mathrm{ng} / \mathrm{ml} \quad(\mathrm{n}=11))$. Collagenase levels in synovial fluid tended to increase with increasing numbers of positive cells, and a positive correlation existed between the degree of collagenase expression in synovial tissue and the collagenase concentrations in synovial fluid.

RELATIONSHIP BETWEEN CONCENTRATIONS OF COLLAGENASE AND TIMP-1 IN SYNOVIAL FLUID In 35 synovial fluid samples measured, no positive correlation was found between the concentrations of collagenase and TIMP-1 $(r=0 \cdot 155, \mathrm{p}=0 \cdot 3744)$.

RELATIONSHIP BETWEEN COLLAGENASE ACTIVITIES AND CONCENTRATIONS OF TIMP-1 IN SYNOVIAL FLUID

We found no obvious relationship between the collagenase activities and the concentrations of TIMP-1 in 23 synovial fluid samples measured $(r=0 \cdot 235, \mathrm{p}=0 \cdot 2814)$ (fig 4$)$.

RELATIONSHIP BETWEEN COLLAGENASE ACTIVITIES AND THE RATIOS OF COLLAGENASE CONCENTRATION TO TIMP-1 IN SYNOVIAL FLUID Figure 5 illustrates the relationship between collagenase activities and the ratios of the concentrations of collagenase and TIMP-1 in 21 synovial fluid samples. There was a strong

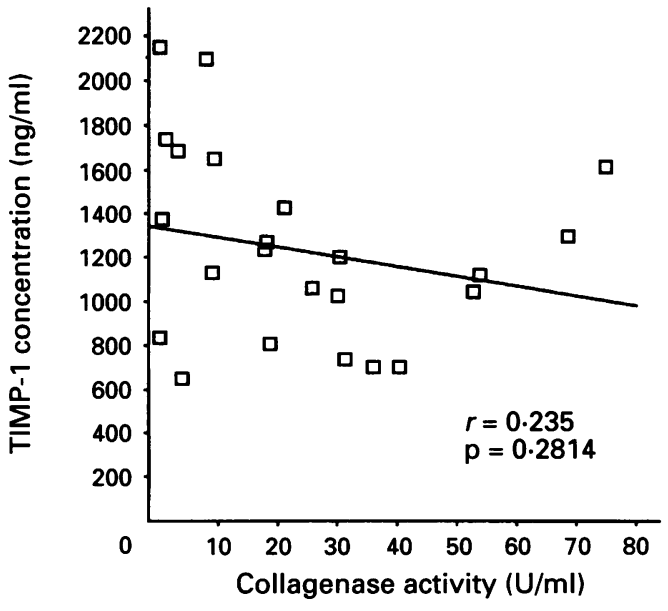

Figure 4 Relationship between collagenase activities and TIMP-1 concentrations in synovial fluid.

positive correlation between collagenase activity and these ratios $(r=0.73, \mathrm{p}=0.0001)$.

\section{Discussion}

This study has shown: (i) collagenase concentrations in synovial fluid did not correlate with C reactive protein or collagenase concentrations in serum; (ii) collagenase levels in synovial fluid correlated positively with the degree of synovial inflammation; (iii) collagenase levels in synovial fluid increased with increasing numbers of cells positive for the expression of collagenase as demonstrated by immunohistochemical staining; (iv) no positive correlation between collagenase and TIMP-1 concentrations; (v) collagenase activity did not correlate with TIMP-1 concentrations, but (vi) did correlate strongly with the ratios of the concentrations of collagenase and TIMP-1.

In this study we examined collagenase concentrations in paired synovial fluid and serum samples taken from RA patients. No obvious relationship existed between the levels of collagenase in synovial fluid and serum, and the concentrations in synovial fluid correlated with neither $C$ reactive protein concentrations in the serum nor ARA Stage or Class of disease progression. These data imply that synovial fluid collagenase concentration cannot be used as a marker for systemic disease activity in RA.

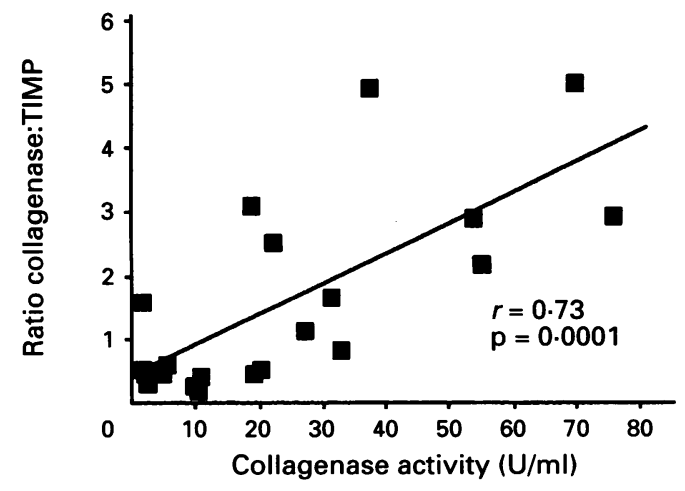

Figure 5 Relationship between collagenase activities and the ratios of the concentration of collagenase to that of TIMP-1 in synovial fluid. 
We also compared synovial fluid concentrations with the degree of synovial inflammation. Using in situ hybridisation, Firestein et al reported a positive correlation between the degree of synovial inflammation and expression of collagenase mRNA in synovial tissue. ${ }^{29}$ In our study, concentrations of collagenase in synovial fluid correlated with the degree of synovial inflammation. These data complement previous reports that cytokines derived from inflammatory cells, such as interleukin-1 and tumour necrosis factor, can modulate the amount of collagenase synthesised. ${ }^{30-34}$ While synovial fluid concentration of collagenase cannot be used as a marker for systemic disease activity, it can be used as a marker for the degree of synovial inflammation in the joint from which the sample is aspirated.

Collagenase has been immunolocalised in hyperplastic lining cells in rheumatoid synovium using an immunohistochemical method, ${ }^{6}$ and in situ hybridisation studies have also demonstrated production of collagenase mRNA in rheumatoid synovial lining cells. ${ }^{29} 3536$ We applied monospecific antibodies against collagenase to synovium, cartilage, and the cartilage-pannus junction in the RA joint and were able to immunolocalise collagenase in synovial lining cells; very little staining was found in chondrocytes and fibroblasts at the cartilage-pannus junction. Woolley et al reported immunolocalisation of collagenase in the extracellular matrix at the cartilage-pannus junction, but the cells producing collagenase could not be identified. ${ }^{5}$ We graded synovial tissue according to the number of cells shown by immunohistochemical staining to express collagenase, and compared the grades with the concentrations of collagenase found in the synovial fluid. The concentrations of collagenase in the synovial fluid tended to increase with increasing numbers of positively staining cells.

Three apparently distinct processes are involved in cartilage degradation: hypertrophic synovial cells produce MMPs and release them into synovial fluid, where the enzymes degrade the articular cartilage matrix; fibroblasts at the cartilage-pannus junction secrete MMPs and directly degrade the cartilage matrix; and chondrocytes produce and secrete MMPs and then digest their own matrix. Fell et al reported marked degradation of both proteoglycans and collagen of the matrix when living cartilage was placed in contact with synovium, ${ }^{9}$ and Sapolsky et al have shown that chondrocytes of normal adult cartilage produce proteinases that are capable of degrading proteoglycans. ${ }^{7}$ Ehrlich et al demonstrated a collagenolytic enzyme in osteoarthritic and normal human cartilage, ${ }^{8}$ and Shinmei et al have suggested that autocrine modulation of chondrocyte metabolism may be the cause of cartilage breakdown in OA. ${ }^{37}$

In the present study, collagenase was immunolocalised in synovial lining cells, but very little staining was found in the chondrocytes of articular cartilage and in the fibroblasts at the cartilage-pannus junction. A relationship was demonstrated between the degree of expression of collagenase in synovial tissue and the concentration of collagenase in synovial fluid. These data suggest that, as far as collagenase is concerned, synovial cells are more important in the breakdown of the cartilage matrix than are chondrocytes. It has also been suggested that collagenase participates in the destruction of the entire cartilage surface, not just that of a localised area such as the cartilage-pannus junction. Hasty et al studied rats with collagen induced arthritis and proposed that chondrocytes may play a direct part in the earliest stages of degradation of their own matrix. ${ }^{38}$ In the present study, we obtained all samples at the time of total knee joint replacement surgery and thus cannot comment on the importance of chondrocytes in the initial stage of RA. Our findings do suggest that, in advanced RA, most of the collagenase is produced in synovial lining cells and released into synovial fluid, where it degrades the articular cartilage matrix.

Both active and latent collagenase have been shown to be present in rheumatoid synovial fluid, ${ }^{39} 40$ and an inhibitor of collagenase demonstrated in newborn rabbit bone, TIMP, has been shown to bind to activated collagenase. ${ }^{18} 19$ It has been proposed that an imbalance between MMPs such as collagenase and TIMP contributes to the pathogenesis of $\mathrm{OA}^{20}$ We measured collagenase activities and TIMP-1 concentrations in synovial fluid, using an assay that included activation with trypsin. It is known that collagenase inhibitors such as TIMP-1, TIMP-2, and $\alpha_{2}$-macroglobulin may be inactivated by trypsin treatment, and thus the results of our assay may be overestimates. However, little active collagenase has been detected in synovial fluid, ${ }^{41}$ and the assay is not capable of measuring collagenase activity without the addition of an activating agent such as trypsin. We found no positive correlation between collagenase and TIMP-1 concentrations. This result is consistent with that reported by Clark et al. ${ }^{42}$

It has been reported that procollagenase is secreted as both a minor glycosylated form and a major polypeptide. ${ }^{43}$ Both the $57 \mathrm{kDa}$ and the $52 \mathrm{kDa}$ procollagenase could be activated by trypsin, generating their respective $47 \mathrm{kDa}$ and $42 \mathrm{kDa}$ active enzyme forms. ${ }^{43}$ In the present study, the extent to which procollagenase contributes to the total (latent + active) concentration of collagenase in synovial fluid could not be determined; even when the concentration of total collagenase was assayed, an accurate molarity could not be calculated. It has previously been reported that no appreciable amount of apparently active collagenase was present in synovial fluid, the majority of the collagenase being in the latent form. ${ }^{41}$ If this is so, the ratio of concentrations of collagenase and TIMP will correspond approximately with the ratio of the molarity between them. We found a strong positive correlation between collagenase activity and the collagenase:TIMP ratio $(r=0.73, p=0.0001)$. These data support the concept that an imbalance between MMP and TIMP is responsible for the degradation of extracellular matrix which occurs in RA. 
We thank Dr A Rikimaru, Narugo National Hospital of Miyagi, and Dr K Sato, Tohoku Rosai Hospital of Sendai, for providing samples obtained from patients. We also thank Mr K Shoji for his skilful help with photographs.

1 Matrisian L. Metalloproteinases and their inhibitors in matrix remodelling. Trends Genet 1990; 6: 121-5.

2 Evanson J M, Jeffrey J J, Krane S M. Human collagenase: identification and characterization of an enzyme from rheumatoid synovium in culture. Science 1967; 158: 499-502.

3 Evanson J M, Jeffrey J J, Krane S M. Studies on collagenase from rheumatoid synovium in tissue culture. $\mathcal{f}$ Clin Invest 1968; 47: 2639-51.

4 Harris E D Jr, DiBona D R, Krane S M. Collagenase in human synovial fluid. $f$ Clin Invest 1969; 48: 2104-13.

5 Woolley D E, Crossley M J, Evanson J M. Collagenase at sites of cartilage erosion in the rheumatoid joint. Arthritis Rheum 1977; 20: 1231-9.

6 Okada Y, Gonoji Y, Nakanishi I, Nagase H, Hayakawa T. Immunohistochemical demonstration of collagenase and tissue inhibitor of metalloproteinases (TIMP) in synovial
lining cells of rheumatoid synovium. Virchows Arch B Cell Pathol 1990; 59: 305-12.

7 Sapolsky A T, Keiser H, Howell D S, Woessner J F Jr. Metalloproteinasesss of human articular cartilage that digest cartilage proteoglycan at neutral and acid $\mathrm{pH}$. 7 Clin Invest 1976; 58: $1030-41$.

8 Ehrlich M G, Mankin H J, Jones H, Wright R, Crispen C. Vigliani $G$. Collagenase and collagenase inhibitors in osteoarthritis and normal human cartilage. 7 Clin Invest osteoarthritis and

9 Fell $\mathrm{H} \mathrm{B}$, Jubb R W. The effect of synovial tissue on the breakdown of articular cartilage in organ culture. Arthritis Rheum 1977; 20: 1359-71.

10 Nagase H, Jackson R C, Brinckerhoff C E, Vater C A, Harris E D Jr. A precursor form of latent collagenase produced in a cell-free system with mRNA from rabbit synovial cells. F Biol Chem 1981; 256: 11951-4.

11 Vaes $\mathrm{G}$. The release of collagenase as an inactive proenzyme by bone explants in culture. Biochem $\mathcal{f}$ 1972; 126: 275-89.

12 Stricklin G P, Bauer E A, Jeffrey J J, Eisen A Z. Human skin collagenase: isolation of precursor and active forms from both fibroblasts and organ cultures. Biochemistry 1977; 16: $1607-15$.

13 Shinkai H, Nagai Y. A latent collagenase from embryonic human skin explants. F Biochem 1977; 81: 1261-8.

14 Sakamoto S, Sakamoto M, Matsumoto A, Goldhaber $P$, Glimcher M J. Latent collagenase from culture medium of embryonic chick bones. FEBS Lett 1978; 88: 53-8.

15 Vater C A, Mainardi C L, Harris E D. Activation in vitro of rheumatoid synovial collagenase from cell cultures. f Clin Invest 1978; 62: 987-92.

16 Murphy G, Cockett M I, Stephens P E, Smith B J, Docherty A J P. Stromelysin is an activator of procollagenase. Biochem 7 1987; 248: 265-8.

17 Van Wart H E, Birkedal-Hansen H. The cystein switch: a principle of regulation of metalloproteinase activity with principle of regulation of metalloproteinase activity with potential applicability to the entire matrix metallo-
proteinase gene family. Proc Natl Acad Sci USA 1990; 87: proteinase

18 Cawston T E, Galloway W A, Mercer E, Murphy G, Reynolds J J. Purification of rabbit bone inhibitor of collagenase. Biochem $\mathcal{F}$ 1981; 195: 159-65.

19 Cawston T E, Murphy G, Mercer E, Galloway W A Hazleman B L, Reynolds J J. The interaction of purified rabbit bone collagenase with purified rabbit bone metalloproteinase inhibitor. Biochem $\mathcal{F}$ 1983; 211: 313-8.

20 Dean D D, Martel-Pelletier J, Pelletier J P, Howell D S, Woessner J F. Evidence for metalloproteinase and metalloproteinase inhibitor imbalance in human osteoarthritic cartilage. $\mathcal{F}$ Clin Invest 1989; 84: 678-85.

21 Birkedal-Hansen B, Birkedal-Hansen H, Robert E T, Ajit S B, Birkedal-Hansen $\mathrm{H}$. Monoclonal antibodies to human fibroblast collagenase. Inhibitor of enzymatic activity, affinity purification of the enzyme, and evidence activity, affinity purification of the enzyme, and evidence for clustering of epitopes in the $\mathrm{NH}_{2}$-terminal end

22 Arnett F C, Edworthy S M, Bloch D A, et al. The American Rheumatism Association 1987 revised criteria for the classification of rheumatoid arthritis. Arthritis Rheum 1988; 31: 315-24.
23 Kodama S, Yamashita K, Kishi J, Iwata K, Hayakawa T. A sandwich enzyme immunoassay for collagenase inhibitor using monoclonal antibodies. Matrix 1989; 9: 1-6.

24 Kodama S, Iwata K, Iwata H, Yamashita K, Hayakawa $T$. Rapid one-step sandwich enzyme immunoassay for tissue inhibitor of metalloproteinases: an application for rheumatoid arthritis serum and plasma. $\mathcal{f}$ Immunol Methods 1990; 127: 103-8.

25 Hayakawa T, Yamashita K, Kodama S, Iwata H, Iwata K. Tissue inhibitor of metalloproteinases and collagenase activity in synovial fluid of human rheumatoid arthritis. Biomedical Res 1991; 12: 169-73.

26 Rooney M, Whelan A, Feighery C, Breshinhan B. Changes in lymphocyte infiltration of membrane and the clinical course of rheumatoid arthritis. Arthritis Rheum 1989; 32: $361-9$

27 Terato $\dot{K}$, Hashida R, Miyamoto $\mathrm{K}$, et al. Histological, immunological and biochemical studies on type II collagen-induced arthritis in rats. Biomedical Res 1982; 3: 495-505.

28 Steinbrocker O, Traeger C H, Batterman R C. Therapeutic criteria in rheumatoid arthritis. $\mathscr{f} A M A$ 1949; 140: 659-72.

29 Firestein G S, Paine M M, Littman B H. Gene expression collagenase, tissue inhibitor of metalloproteinases, complement, and HLA-DR) in rheumatoid arthritis and osteoarthritis synovium: quantitative analysis and effect of intraarticular corticosteroids. Arthritis Rheum 1991; 34: 1094-105.

30 Murphy G, Reynolds J J, Werb Z. Biosynthesis of tissue inhibitor of metalloproteinases by human fibroblasts in inhibitor of metalloproteinases by human fibroblasts in 13-acetate and interleukin 1 in parallel with collagenase. 13-acetate and interleukin 1 in p

31 Mizel S B, Dayer J M, Krane S M, Merenhagen S E. Stimulation of rheumatoid synovial cell collagenase and prostaglandin production by partially purified lymphocyte-activating factor (interleukin 1). Proc Natl Acad Sci USA 1981; 78: 2474-7.

32 Dayer J M, Beutler B, Cerami A. Cachectin/tumor necrosis factor stimulates collagenase and prostaglandin $E_{2}$ production by human synovial cells and dermal fibroblasts. $\mathcal{F}$ Exp Med 1985; 162: 2163-8.

33 Postlethwaite A E, Raghow R, Stricklin G P, Poppletoro H, Seyer J M, Kang A H. Modulation of fibroblast functions by interleukin 1: increased steady-state accumulation of type 1 procollagen messenger RNAs and stimulation of type 1 procollagen messenger RNAs and stimulation of other functions but not chemotaxis by human
recombinant interleukin $1 \alpha$ and $\beta$. $¥$ Cell Biol 1988; 106: recomb.

34 McCachren S S, Greer P K, Niedel J E. Regulation of human synovial fibroblast collagenase messenger RNA by interleukin-1. Arthritis Rheum 1989; 32: 1539-45.

35 McCachren S S, Haynes B F, Niedel J E. Localization of collagenase mRNA in rheumatoid arthritis synovium by in situ hybridization histochemistry. $\mathcal{F}$ Clin Immunol 1990; 10: $19-27$.

36 Gravallese E M, Darling J M, Ladd A L, Katz J N, Glimcher L $\mathrm{H}$. In situ hybridization studies of stromelysin and collagenase messenger RNA expression in rheumatoid synovium. Arthritis Rheum 1991; 34: 1076-84.

37 Shinmei M, Masuda K, Kikuchi T, Shimomura Y, Okada Y. Production of cytokines by chondrocytes and its role in proteoglycan degradation. $\mathcal{f}$ Rheumatol and its role in proteoglyca

38 Hasty K A, Reife R A, Kang A H, Stuart J M. The role of stromelysin in the cartilage destruction that accompanies

39 Abe S, Nagai Y. Evidence for the presence of a latent form of collagenase in human rheumatoid synovial fluid. f Biochem 1972; 71: 919-22.

40 Wize J. A latent collagenase from rheumatoid synovial fluid: purification and partial characterization. Biochim Biophys Acta 1980; 615: 199-207.

41 Abe S, Shinmei M, Nagai Y. Synovial collagenase and joint diseases: the significance of latent collagenase with special reference to rheumatoid arthritis. $\mathcal{F}$ Biochem 1973; 73: 1007-11.

42 Clark I M, Powell L K, Ramsey S, Hazleman B L, Cawston T E. The measurement of collagenase, tissue inhibitor of metalioproteinases (TIMP), and collagenaseTIMP complex- in synovial fluids from patients with TiMP complex. in synovial fluids from patients with 1993; 36: 372-9.

43 Goldberg G I, Wilhelm S M, Kronberger A, Bauer E A, Grant G A, Eisen A Z. Human fibroblast collagenase. f Biol Chem 1986; 261: 6600-5. 